\title{
Washing machine injury of middle finger: a case report and review of the literature
}

\begin{abstract}
Washing machines are gradually being popular in many countries and regions. Washing machine injuries is not uncommon. The author reports a case of middle finger injury caused by washing machine when an attempt is made to remove the clothes from the machine. The fingertip of the right middle finger was amputated not completely, which was connected by nerve and blood vessel bundles in the radial side of the middle finger. Due to the avulsion rotation stress, the contusion of skin and muscles; fractures and degloving injuries occur. Replantation was attempted to carry out on the day that the patient was injured 1 hour later. Complete survival was achieved. Some safety features should be improved to prevent washing machine injuries to people.
\end{abstract}

Keywords: washing machine, injury, fingertip, avulsion, replantation
Volume 4 Issue 3 - 2017

\author{
Yongtao Zhang \\ Department of Orthopedics, Hebei University of Engineering, \\ China
}

Correspondence: Yongtao Zhang , Department of Orthopedics, Affiliated Hospital of Hebei University of Engineering Congtai Road NO.8I. Handan, Hebei, 056002 , China, Email zyt8II003@I26.com

Received: October 30,2016 | Published: May 19, 2017

\section{Introduction}

Approximately $95 \%$ of households in urban and $60 \%$ of households in rural areas had a fully automatic or semiautomatic washing machine in China. As the design of washing machine has changed in recent times, most of the reports are of injuries caused by wringer washing machines. There were 19109 injuries from 1993 to 2000 due to washing machines, according to the United States Consumer Product Safety Commission. ${ }^{1}$ There is a wide variety in type and degree of injuries from these washing machines. They range in extent from slight bruises and lacerations of the fingers and hand, through crushing injuries to soft tissues and muscle, erosion of the superficial and deep structures of the skin, fractures of bones up to and including occasional fatalities. The present study documents a case of injury to the middle finger caused by washing machine. This is caused when the man was trying to unload the contents while the machine was still spinning.

\section{Case report}

A 34-year-old man was admitted to orthopedic center of the Central Hospital of Handan with a not completely amputated fingertip from his middle finger. The patient is eager to restore the length and functions of his damaged middle finger to the original state. His fingertip was connected by nerve and blood vessel bundles in the radial side of the middle finger Figure 1A and skin of the palm side of finger Figure 1B. The injury was sustained while attempting to remove the clothes from the semi-automatic washing machine. He had sustained the avulsion fracture of the distal phalanx of his middle finger (Figure 1A). The skin of the fingertip is pale (Figure 1B) and hypothermia. Surgery was performed under axillary block anesthesia. Minimal debridement was applied to only a part of the skin. Blood vessels and nerve avulsion injuries were serious. It is difficult to replant the fingertip without a sufficient blood vessels supply. It was trimmed under the microscope. The replantation was considered appropriate. The distal phalanx was reduced and fixed. The replantation of the fingertip was decided to carry out on the day that the patient was injured 1hour later. After replantation, the skin in the fingertip was rosy (Figure 1C) and warmer compared with it to be replanted. The wound healed 2 weeks after the injury. No systemic problem occurred afterward, the patient was discharged 3weeks after injury. No necrosis was present. Complete survival was achieved (Figure 2).

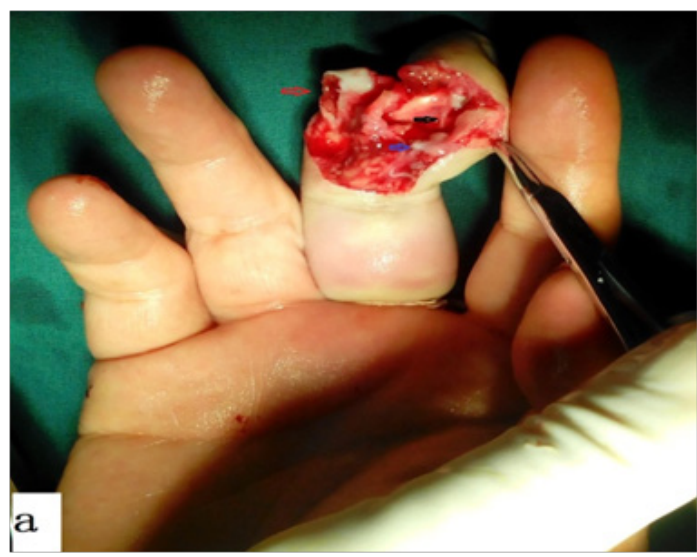

Figure IA The not completely amputated fingertip (The black and blue arrows indicate the injured artery and nerve; the red arrow indicates the avulsion fracture.).

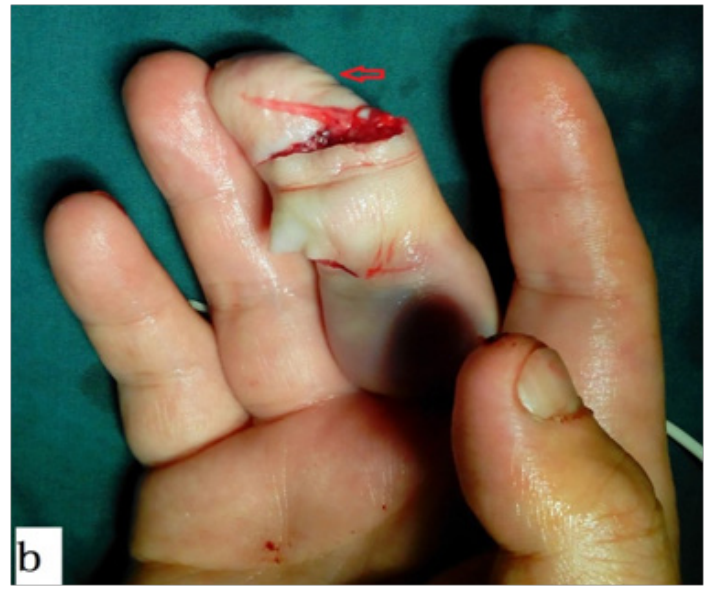

Figure IB The pale fingertip before replantation. 


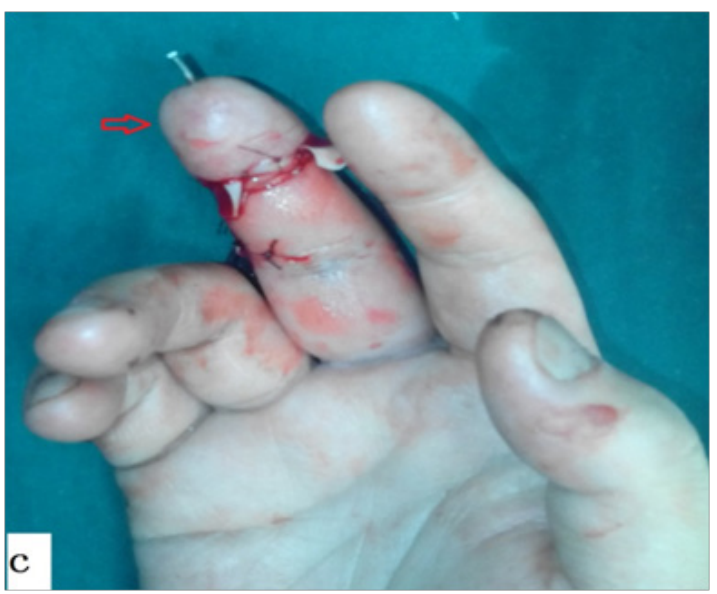

Figure ICThe rosy fingertip after replantation.

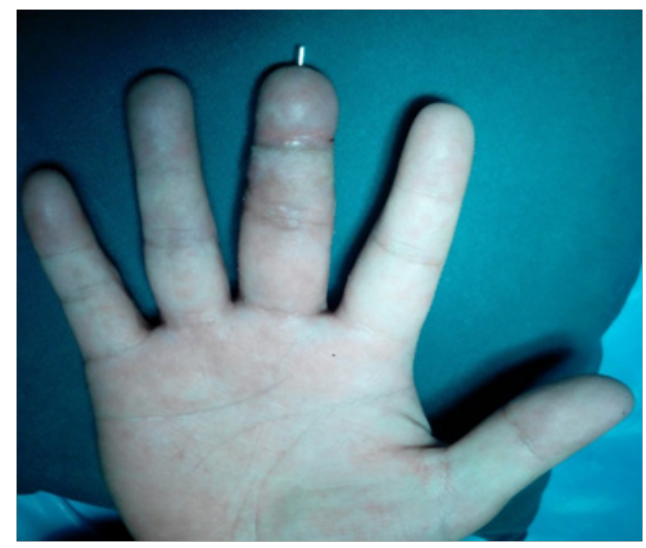

Figure $\mathbf{2}$ The survival fingertip at two months after surgery.

\section{Discussion}

Washing machines have been part of the household. Washing machine injuries occur when attempts are made to remove clothes from the machine and the hand gets entangled in spinning laundry, leading to soft tissue injuries and fractures. These injuries occur most in children according to the previous reported study. ${ }^{2}$ The present washing machine injury occurs in adult is relatively rare. The distal portion of finger is exposed to a high risk of amputation. Due to the avulsion injuries, replantation can be difficult for the tissue of an not completely amputated distal portion of a finger. ${ }^{3,4}$ The severity of injury, which occurs due to the washing machine, is not obvious initially, but only a few hours later. In an animal study, ${ }^{5}$ they found maximum damage to tissues at 24 hours, although it began at three to five hours. These injuries that can occur include: friction injuries; compression causing contusion of skin and muscles; fractures and haematomas, and degloving injuries. ${ }^{6}$

In present report, there also occur the injuries of skin degloving and fracture. The replantation was carried out on the day that the patient was injured 1 hour later. Replantation is effective to avoid the maximum damage in the early stage and useful for the survival of the fingertip. Washing machines are gradually being popular in the less developed regions. Washing machine injuries occur sometimes in these regions. In most machines there is a safety mechanism to stop the drum from spinning once the loading door is opened. But usually there is a time delay and the machine continues to spin even when the door is open. Given the risk, there are various measures that would prevent washing machine injuries to people by improved safety features such as a triggering system, sensitive enough to detect even a small opening of the lid.

\section{Acknowledgements}

None.

\section{Conflict of interest}

The author declares no conflict of interest.

\section{References}

1. Warner BL, Kenney BD, Rice M. Washing machine related injuries in children: a continuing threat. Inj Prev. 2003;9(4):357-360.

2. Suresh SS. Washing machine injuries of the upper extremity: case reports with a review of the literature. Sultan Qaboos Univ Med J. 2008;8(1):8992.

3. Yamano Y. Replantation of the amputated distal part of the fingers. $J$ Hand Surg Am.1985;10(2):211-218.

4. Tamai S. Twenty years' experience of limb replantation-review of 293 upper extremity replants. J Hand Surg Am. 1982;7(6):549-556.

5. Adams JP, Fowler FD. Observations in wringer injuries. An experimental study. J Bone Joint Surg Am. 1961;43-A:1179-1186.

6. Golden GT, Fisher JC, Edgerton MT. "Wringer arm" reevaluated: a survey of current surgical management of upper extremity compression injuries. Ann Surg. 1973;177(3):362-369. 